\title{
The activity of selected glycosidases in salivary gland tumors
}

\author{
Marcin Bierc $^{1}$, Lukasz Minarowski ${ }^{2}$, Lukasz Woźniak ${ }^{1}$, Sylwia Chojnowska ${ }^{3}$, \\ Malgorzata Knas ${ }^{4}$, Slawomir Szajda ${ }^{5}$, Krzysztof Zwierz $^{3}$
}

\author{
Departments of: ${ }^{1}$ Oral Surgery, ${ }^{2}$ Lung Diseases and Tuberculosis, ${ }^{4}$ Cosmetology, ${ }^{5}$ Pharmecutical \\ Biochemistry, Medical University of Bialystok, Poland \\ ${ }^{3}$ Post-secondary School of Public Health, Lomza, Poland
}

\begin{abstract}
The monitoring of the patients after salivary gland tumors surgery is an important clinical issue. Still imperfect diagnostic procedures also remain a challenge for searching new sensitive and specific biomarkers of neoplastic processes in salivary glands. The aim of the presented study was an the assessment of the activity of HEX, with its isoforms HEX-A and HEX-B, GLU, GAL, MAN and FUC in salivary gland tumor tissues in comparison to a healthy salivary gland tissues taken during autopsy. A group of 42 patients with benign and malignant salivary gland tumors, aged 25-65 were examined. Fragments of salivary gland tumor tissue, fragments of healthy tissue removed during autopsy, blood serum and saliva were collected from patients with salivary gland tumors and healthy volunteers. In salivary gland tumor tissue the activity of HEX, HEX-A, HEX-B, GAL, FUC was considerably higher than in comparison to healthy salivary gland tissue and ascending trend of activity of GLU, MAN was also noticed. The activity of all lysosomal exoglycosidases in blood serum in patients with salivary gland tumors was considerably higher in comparison to healthy volunteers blood serum. The considerably higher activity of HEX, HEX-A, GLU, GAL, MAN, FUC and descending trend of activity of HEX-B were noticed in saliva of patients with salivary gland tumors in comparison to healthy volunteers. The assessment of HEX in blood serum and saliva of patients with salivary gland tumor can be possibly used in diagnostics and monitoring of salivary glands tumors.
\end{abstract}

Key words: salivary gland tumors, saliva, lysosomal glycosidases, glycoconjugates

\section{Introduction}

The most serious illnesses of salivary glands are tumors, that occur usually in major salivary glands $(80-85 \%)$ [1]. The most frequent are benign glandular epithelium tumors, i.e. adenoma polymorphum, adenolymphoma [2]. Salivary gland neoplasms are not responsive to radiation, thus surgery is the therapeutic method of choice [3].

The monitoring of the patients after salivary gland tumors surgery is an important clinical issue. The possibility of recurrence after incomplete tumor excision is likely. Still imperfect diagnostic procedures also remain a challenge for searching new sensitive and

Correspondence: M. Bierc, Department of Oral Surgery, Medical University of Bialystok, M.C. Sklodowskiej Str. 24A, 15-276 Bialystok, Poland; tel.: (+4885) 7468789,

fax.: (+4885) 7468789, e-mail: bierc@interia.pl specific biomarkers of neoplastic processes in salivary glands $[4,7]$.

The development of tumors can cause a change in activity and structure of enzymes. The alteration in enzymatic activity can occur due to both increased biosynthesis, expulsion to the blood and the presence of necrotic or inflamed foci. Destruction of surrounding tissue is caused by lysosomal exoglycosidases. Exoglycosidases catabolize glycoconjugates (glycoproteins, proteoglycans, glycolipids). Lysosomal exoglycosidases act on the external nonreducing part of oligosaccharide chain of glycoconjugates, thus starting the chain reaction, where the product of the previous reaction becomes a substrate for the next one. The exoglycosidases degrade, in consequence, glycoproteins, proteoglycans, glycolipids that form the cellular membrane and intercellular matrix. Among exoglycosidases there are: $\mathrm{N}$-acetyl- $\beta$-hexosoaminidase (HEX), $\beta$ glucuronidase (GLU), $\beta$-galactosidase (GAL), $\alpha$-mannosidase (MAN) and $\alpha$-fucosidase (FUC) [9-13]. 
Table 1. Statistical analysis of hexosoaminidase (HEX) and its isoforms (HEX-A and HEX-B) activity (expressed in $\mu$ Kat/mg of protein) in patients with salivary gland tumors in comparison to healthy subjects. All variables have normal distribution.

\begin{tabular}{|c|c|c|c|c|c|c|c|c|c|c|}
\hline & & \multicolumn{3}{|c|}{ IEX } & \multicolumn{3}{|c|}{$\mathrm{I} \mathrm{X}-\mathrm{A}$} & \multicolumn{3}{|c|}{$\mathrm{IEX} \mathrm{X}-\mathrm{B}$} \\
\hline & & $\mathrm{n}$ & $\mathrm{x} \pm \mathrm{SD})$ & $\mathrm{p}$ & $\mathrm{n}$ & $\mathrm{x} \pm \mathrm{SD}$ & $\mathrm{p}$ & $\mathrm{n}$ & $\mathrm{x} \pm \mathrm{SD})$ & $\mathrm{p}$ \\
\hline \multirow{2}{*}{ Tissuc } & controls & 22 & $9.1 \pm 2.81$ & \multirow{2}{*}{0.024} & 41 & $6.3 \pm 2.23$ & \multirow{2}{*}{0.06} & 41 & $41.0 \pm 0.88$ & \multirow{2}{*}{0.009} \\
\hline & tumors & 41 & $7.7 \pm 2.72$ & & 41 & $5.4 \pm 2.02$ & & 41 & $2.3 \pm 0.91$ & \\
\hline \multirow{2}{*}{ Saliva } & controls & 41 & $1.3 \pm 0.41$ & \multirow{2}{*}{$<0.001$} & 41 & $1.1 \pm 0.37$ & \multirow{2}{*}{0.003} & 41 & $0.2 \pm 0.09$ & \multirow{2}{*}{$<0.001$} \\
\hline & tumors & 30 & $1.1 \pm 0.29$ & & 30 & $0.8 \pm 0.26$ & & 30 & $0.1 \pm 0.06$ & \\
\hline \multirow{2}{*}{ Serum } & controls & 41 & $101.9 \pm 36.88$ & \multirow{2}{*}{$<0.001$} & 41 & $75.0 \pm 31.98$ & \multirow{2}{*}{$<0.001$} & 41 & $26.9 \pm 9.66$ & \multirow{2}{*}{$<0.001$} \\
\hline & tumors & 41 & $140.5 \pm 22.87$ & & 41 & $98.0 \pm 19.51$ & & 41 & $42.5 \pm 12.22$ & \\
\hline
\end{tabular}

Table 2. Statistical analysis of $\beta$-glucuronidase (GLU), $\beta$-galactosidase (GAL), $\alpha$-mannosidase (MAN) and $\beta$-fucosidase (FUC) activity (expressed in $\mu \mathrm{Kat} / \mathrm{mg}$ of protein) in patients with salivary gland tumors in comparison to healthy subjects. All variables have normal distribution.

\begin{tabular}{|c|c|c|c|c|c|c|c|c|c|c|c|c|c|}
\hline & & \multicolumn{3}{|c|}{ GLU } & \multicolumn{3}{|c|}{ GAL } & \multicolumn{3}{|c|}{ MAN } & \multicolumn{3}{|c|}{ liUC } \\
\hline & & $\mathrm{n}$ & $\mathrm{x} \pm \mathrm{SD}$ & $\mathrm{p}$ & $\mathrm{n}$ & $\mathrm{x} \pm \mathrm{SD}$ & $\mathrm{p}$ & $\mathrm{n}$ & $\mathrm{x} \pm \mathrm{SD}$ & $\mathrm{p}$ & $\mathrm{n}$ & $\mathrm{x} \pm \mathrm{SD}$ & $\mathrm{p}$ \\
\hline \multirow{2}{*}{ Tissue } & controls & 41 & $0.9 \pm 0.28$ & \multirow{2}{*}{$<0.001$} & 41 & $0.3 \pm 0.09$ & \multirow{2}{*}{0.51} & 41 & $0.34 \pm 0.10$ & \multirow{2}{*}{$<0.001$} & 41 & $0.27 \pm 0.10$ & \multirow{2}{*}{0.021} \\
\hline & tumors & 41 & $0.6 \pm 0.19$ & & 41 & $0.3 \pm 0.11$ & & 41 & $0.22 \pm 0.07$ & & 41 & $0.22 \pm 0.09$ & \\
\hline \multirow{2}{*}{ Saliva } & controls & 41 & $0.06 \pm 0.02$ & \multirow{2}{*}{$<0.001$} & 41 & $0.0012 \pm 0.001$ & \multirow{2}{*}{0.02} & 41 & $0.016 \pm 0.009$ & \multirow{2}{*}{0.61} & 41 & $0.006 \pm 0.003$ & \multirow{2}{*}{0.60} \\
\hline & tumors & 30 & $0.04 \pm 0.01$ & & 30 & $0.0018 \pm 0.001$ & & 30 & $0.015 \pm 0.006$ & & 30 & $0.005 \pm 0.003$ & \\
\hline \multirow{2}{*}{ Scrum } & controls & 41 & $24.1 \pm 11.71$ & \multirow{2}{*}{$<0.001$} & 41 & $9.3 \pm 6.82$ & \multirow{2}{*}{$<0.001$} & 41 & $10.8 \pm 6.79$ & \multirow{2}{*}{$<0.001$} & 41 & $15.1 \pm 8.34$ & \multirow{2}{*}{$<0.001$} \\
\hline & tumors & 41 & $38.3 \pm 11.2$ & & 41 & $16.7 \pm 5.71$ & & 41 & $19.6 \pm 7.99$ & & 41 & $24.0 \pm 6.92$ & \\
\hline
\end{tabular}

The aim of the presented study was an the assessment of the activity of HEX, with its isoforms HEX-A and HEX-B, GLU, GAL, MAN and FUC in salivary gland tumor tissues in comparison to a healthy salivary gland tissues taken during autopsy. Moreover the activity of studied glycosidases was assessed in blood serum and saliva taken from patients with salivary gland tumors and in blood serum of healthy volunteers.

\section{Materials and methods}

Patients. The 42 patients with benign and malignant tumors of salivary glands, in age between 25 and 65 , both of sex, not smoking, without concomitant disease, operated in Department of Maxillo-Facial Surgery Medical University in Bialystok and Otolaryngology Department of Provincial Hospital in Bialystok were examined. Autopsy material was derived from Forensic Medicine Department of Medical University in Bialystok.

Salivary gland tissue and saliva. Fragments of salivary gland tumor tissue were collected after the surgical removal of tumor mass. Fragments of healthy tissue were collected from subjects deceased due to non-neoplastic causes during autopsy before 12 hours after death - all the subjects died as a result of sudden death. Saliva samples were taken from patients with salivary gland tumors and healthy volunteers. The taken tissues were immediately frozen in liquid nitrogen and subsequently stored in $-80^{\circ} \mathrm{C}$ until further analysis. After thawing the tissues were homogenized and centrifuged for $20 \mathrm{~min}$. at $12000 \times \mathrm{g}$. Biochemical analyses were performed in collected supernatant. Collected saliva samples were homogenized and stored in $-80^{\circ} \mathrm{C}$ until further analysis.

Blood. The blood samples were taken from patients with salivary gland tumors and healthy individuals in hospital conditions, in fasting state, in volume of $5 \mathrm{ml}$ for clot. The samples were centrifuged for $10 \mathrm{~min}$ at $3500 \times \mathrm{g}$ and obtained serum was stored in $-80^{\circ} \mathrm{C}$ until further analysis.

Enzymes activity. The activities of lysosomal exoglycosidases were estimated by method of Chatterjee et al in Zwierz et al modification [12].

Ethical issues. Research protocol was approved by Bioethics Committee of Medical University in Bialystok (protocol number R-I003/332/2005 i R-I-002/32/2007).

Statistical analysis. Obtained results were tested for normal distribution using Kolomogrov-Smirnov test. For variables with normal distribution independent two-sample t-test was used. For variables with non-normal distribution U-Mann-Whitney test was used. The test were perfomred using Statistica ver. 6.0 (StatSoft, Tulsa, Oklahoma, USA). Statistical significance was considered if $\mathrm{p}<0.05$.

\section{Results}

Detailed results of exoglycosidases activity measurements are presented in Tables 1 and 2 . 

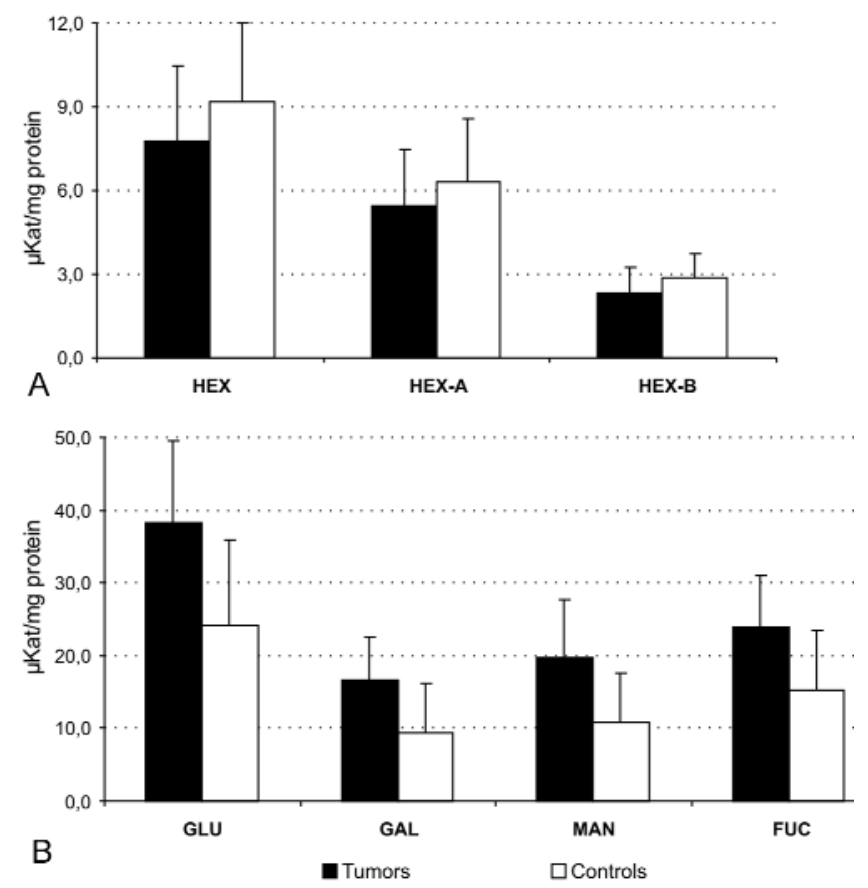

Fig. 1. The activity of lysosomal exoglycosidases: (A) HEX and HEX-A and HEX-B isoenzymes and (B) GLU, GAL, MAN, FUC in resected salivary gland tumor tissue in comparison to healthy tissue obtained during autopsy.

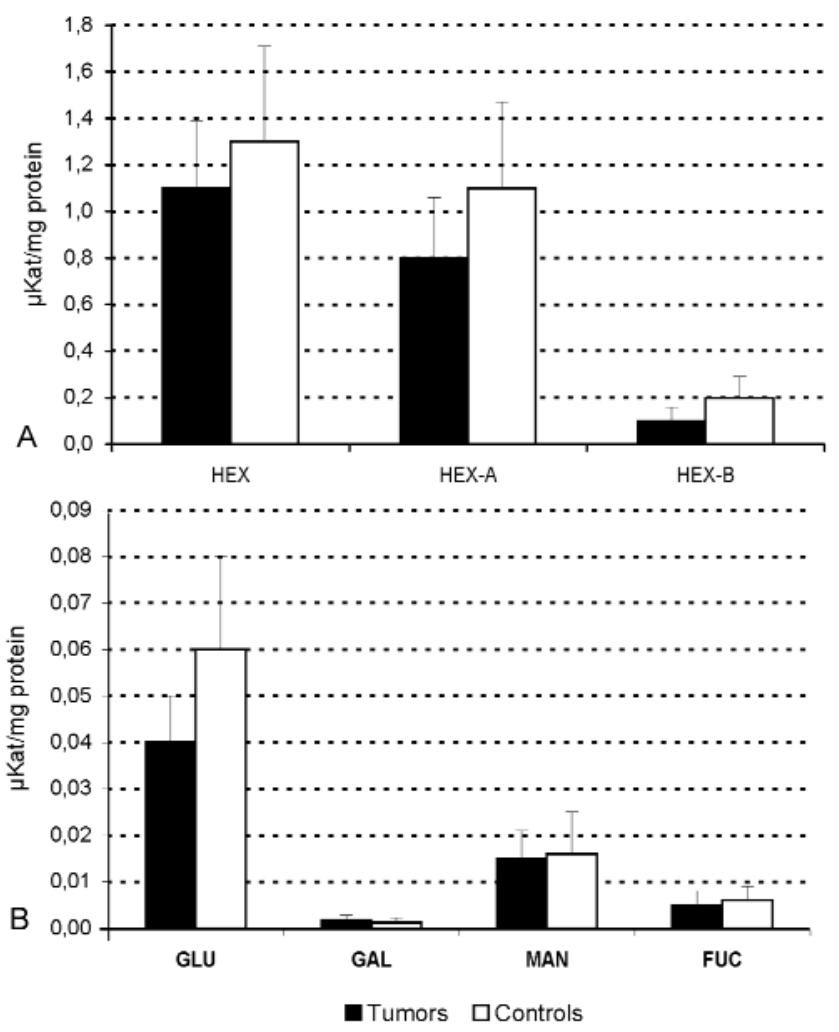

Fig. 2. The activity of lysosomal exoglycosidases: (A) HEX and HEX-A and HEX-B isoenzymes and (B) GLU, GAL, MAN, FUC in saliva of patients with salivary gland tumors in comparison to healthy individuals.
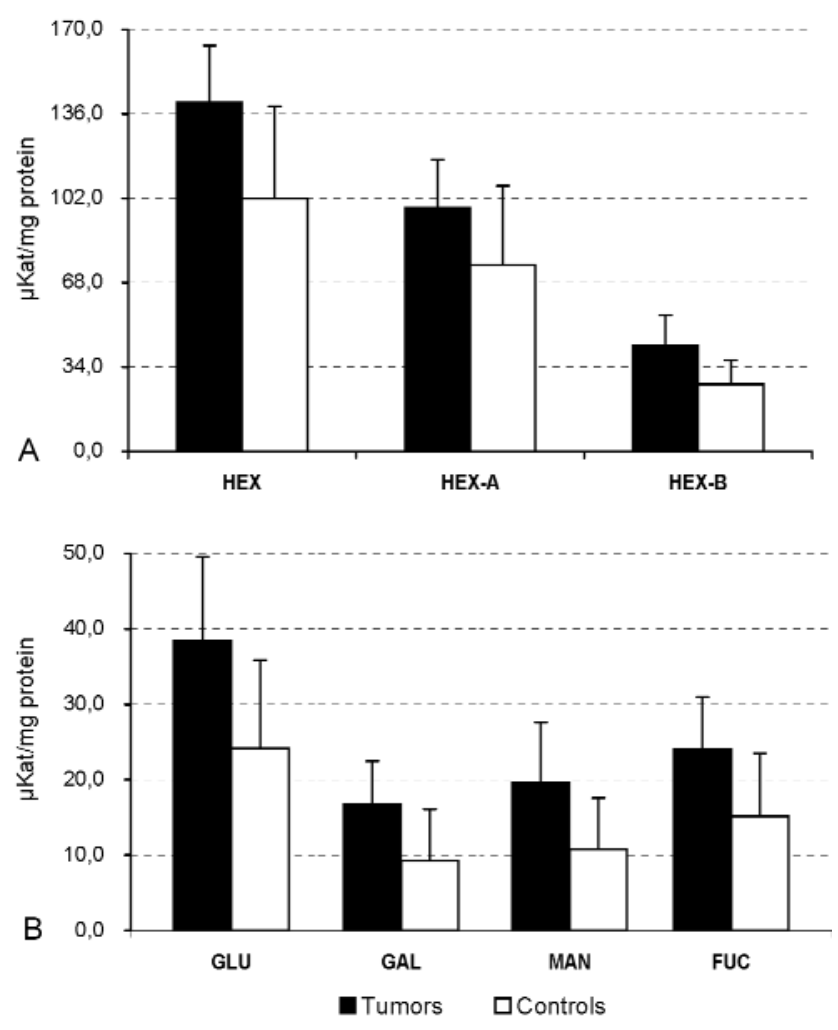

Fig. 3. The activity of lysosomal exoglycosidases: (A) HEX and HEX-A and HEX-B isoenzymes and (B) GLU, GAL, MAN, FUC in serum of patients with salivary gland tumors in comparison to healthy individuals.

In salivary gland tumor tissue the activity of lysosomal exoglycosidases, expressed as nKat $/ \mathrm{mg}$ of protein amounted respectively HEX: $7.7 \pm 2.72 \mathrm{nKat} / \mathrm{mg}$, HEX-A: $5.4 \pm 2.02$ nKat $/ \mathrm{mg}$, HEX-B: $2.3 \pm 0.91$ nKat/mg, GLU: $0.6 \pm 0.19$ nKat $/ \mathrm{mg}$, GAL: $0.3 \pm 0.11$ $\mathrm{nKat} / \mathrm{mg}$, MAN: $0.22 \pm 0.77 \mathrm{nKat} / \mathrm{mg}$, FUC: $0.22 \pm 0.09$ nKat/mg (Fig. 1).

In saliva collected from patients with salivary gland tumors the activity of HEX, HEX-A, HEX-B, GLU, GAL, MAN, FUC amounted respectively: $1.1 \pm 0.29 \mathrm{nKat} / \mathrm{mg}, 0.8 \pm 0.26 \mathrm{nKat} / \mathrm{mg}, 0.1 \pm 0.06$ $\mathrm{nKat} / \mathrm{mg}, \quad 0.04 \pm 0.01 \quad \mathrm{nKat} / \mathrm{mg}, \quad 0.0018 \pm 0.001$ $\mathrm{nKat} / \mathrm{mg}, \quad 0.015 \pm 0.006 \quad \mathrm{nKat} / \mathrm{mg}, \quad 0.005 \pm 0.003$ nKat/mg (Fig. 2).

In blood serum collected from patients with salivary gland tumors the activity of HEX, HEX-A, HEXB, GLU, GAL, MAN, FUC amounted respectively $140.5 \pm 22.87 \mathrm{nKat} / \mathrm{mg}, \quad 98.0 \pm 19.51 \mathrm{nKat} / \mathrm{mg}$, $42.5 \pm 12.22 \mathrm{nKat} / \mathrm{mg}, 38.3 \pm 11.2 \mathrm{nKat} / \mathrm{mg}, 16.7 \pm 5.71$ $\mathrm{nKat} / \mathrm{mg}, \quad 19.6 \pm 7.99 \mathrm{nKat} / \mathrm{mg}, 24.0 \pm 6.92 \mathrm{nKat} / \mathrm{mg}$ (Fig. 3).

In salivary gland tumor tissue the activity of HEX, HEX-A, HEX-B, GAL, FUC was considerably lower in comparison to healthy salivary gland tissue, as well as activity of GLU, MAN and FUC. 
Significantly lower activity of HEX, HEX-A, HEXB, GLU and MAN were noticed in saliva of patients with salivary gland tumors in comparison to healthy volunteers. The activity of GLU in saliva was significantly higher in patients with salivary gland tumors.

The activity of all lysosomal exoglycosidases in blood serum in patients with salivary gland tumors was considerably higher in comparison to healthy volunteers blood serum.

\section{Discussion}

Glycoconjugates undergo constant metabolism concerned with degradation of old and synthesis of new particles. Degradation of glycoconjugates in lysosomes is performed by lysosomal exoglycosidases HEX, HEX-A, HEX-B, GLU, GAL, MAN and FUC.

The intensification of catabolism, typical for neoplastic process, expressed by elevated activity of lysosomal exoglycosidases in tumor comparing to healthy tissue, represent a differential factor. The elevated activity of lysosomal exoglycosidases in the blood and saliva can be of diagnostic and prognostic importance [1-4].

Above statement can be the cause for further investigation, whether the difference in lysosomal activity of exoglycosidases can be used in diagnostics and monitoring of salivary glands tumors.

The activity of lysosomal exoglycosidases was confirmed in every examined material (salivary gland tumor tissue, healthy salivary gland tissue, blood serum and saliva). HEX was the most active lysosomal exoglycosidase in tissue of salivary gland tumor, blood serum and saliva of patients with tumor $[12,13]$. Tumors of salivary glands and associated inflammation increase biosynthesis and movement of lysosomal exoglycosidases from tumor tissue to blood and saliva. The assessment of lysosomal exoglycosidases in tissue of salivary gland tumor has a great cognitive and certain diagnostic value [14]. Our studies are one of few attempts to assess the usability of exoglycosidases activity measurements for diagnosis of salivary glands tumors. The assessment of HEX in blood serum and saliva of patients with salivary gland tumor can be possibly used in diagnostics and monitoring of salivary glands tumors.

\section{References}

[ 1] Copelli C, Bianchi B, Ferrari S, Ferri A, Sesenna E. Malignant tumors of intraoral minor salivary glands. Oral Oncol. 2008;44(7):658-63

[2] Kawata R, Lee K, Araki M, Takenaka H. Safety and usefulness of an electric knife during surgery for parotid benign tumor: postoperative facial paresis and its risk factors. Acta Otolaryngol. 2007;127(9):966-9.

[3] Hong KH, Yang YS. Intraoral approach for the treatment of submandibular salivary gland mixed tumors. Oral Oncol. 2008;44(5):491-5.

[ 4] Young CL, Sei Young L, Kyubo K, Jin Seok L, Bon Seok K, Hyang AeS, Eun CC. Conservative parotidectomy for the treatment of parotid cancers. Oral Oncol. 2005;41:10211027.

[5] Gurney AG, Eisele DW, Weinberg V, Shin E, Lee Nancy. Adenoid cystic carcinoma of the major salivary glands treated with surgery and radiation. Laryngoscope. 2005;115:12781281.

[ 6] Mendehall WM, Morris CG, Amdur RJ, et al. Radiotherapy alone or combined with surgery for salivary gland carcinoma. Cancer. 2005; 103:2544-2550.

[ 7] Bell RB, Dierks EJ, Homer L, et al. Management outcome of patients with malignant salivary gland tumors. J Oral Maxillofac Surg. 2005;63:917-928.

[ 8] World Health Organization Classification of Tumors, Pathology and Genetics of Head and Neck Tumours. IARC Press, Lyon, 2005.

[ 9] Wielgat P, Walczuk U, Szajda S, Bien M, Zimnoch L, Mariak Z, Zwierz K. Activity of lysosomal exoglycosidases in human gliomas. J Neurooncol. 2006;80:243-9.

[10] Zwierz K, Gindzieński A, Ostrowska L, Glowacka D, Porowski T. Degradation of glycoconjugates in human gastric mucous membrane. Acta Med Hung. 1981:38;145-52.

[11] Chatterjee S, Velicer LL, Sweeley CC. Glycosphingolipid glycosol hydrolases and glycosidases of synchronized human KB cells. J Biol Chem. 1975;250:4972-9.

[12] Zwierz K, Gindzieński A, Ostrowska L, StankiewiczChoroszucha B. Metabolism of glycoconjugates in human gastric mucosa a review. Acta Med Hung. 1989:46;275-88.

[13] Borzym-Kluczyk M, Olszewska E, Radziejewska I, Lewszuk A, Zwierz K. Isoenzymes of N-acetyl-beta-hexosaminidase in human pleomorphic adenoma and healthy salivary glands: a preliminary study. Clin Chem Lab Med. 2008;46(1):131-136.

[14] Gossrau R. Indoxyl alfa-D-galactoside as the temporarily last substrate for glycosidase histochemistry. The present state of the art in histochemical glycosidase research using indoxyl glycosidas. Folia Histochem Cytobiol. 1990;28(3):129-43.

Submitted: 28 December, 2009 Accepted after reviews: 19 July, 2010 